\section{Photoenzymatic Catalysis Paves the Way for the Synthesis of Enantioenriched Tertiary Amines}
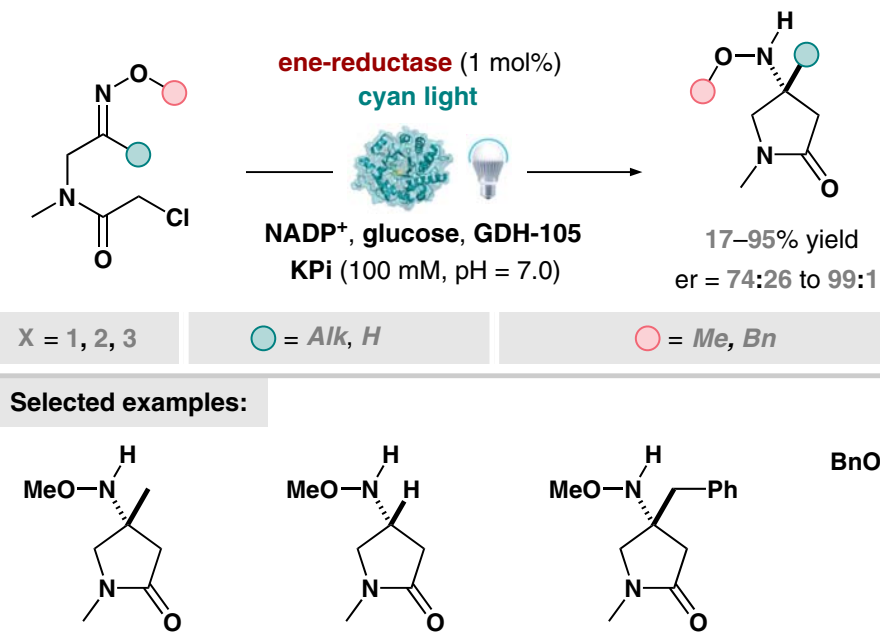

$\mathrm{O}=\mathrm{A} / \mathrm{k}, \mathrm{H}$

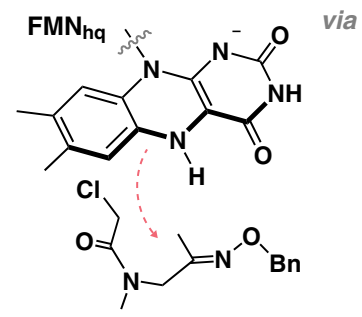

charge transfer
Category

Organo- and

Biocatalysis

Key words

ene-reductases

flavines

tertiary amines

amines

photoenzymatic

catalysis

95\% yield, er $=99: 1 \quad 99 \%$ yield, er $=74: 26 \quad 95 \%$ yield, er $=99: 1 \quad 83 \%$ yield, er $=99: 1 \quad 17 \%$ yield, er $=89: 11$

Follow-up transformations:

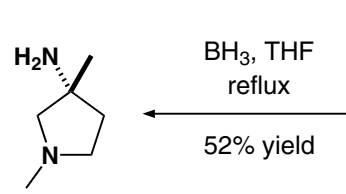<smiles>CN1C[C@](C)(NOc2ccccc2)CC1=O</smiles>

$88 \%$ yield

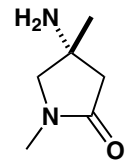

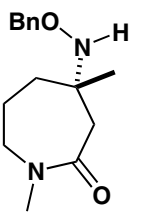

Significance: Hyster and co-workers disclose a photoenzymatic synthesis of enantioenriched $\alpha$ tertiary amines starting from $\mathrm{O}$-alkyloximes, which readily act as electron donors for the formation of charge-transfer (CT) complexes with flavoenzymes. Photoexcitation then leads to radical formation, which subsequently enables the intramolecular addition to the oxime, generating the desired tertiary amine products. Generally, very high enantiomeric ratios were observed by using engineered versions of GluEr-T36A- and NCR-enzymes, obtained by sitesaturation mutagenesis. The resulting hydroxylamine products could, furthermore, be converted into useful compounds in follow-up transformations, giving reduced or ring-opened derivatives.
Comment: Building on their pioneering work (Science 2019, 364, 1166; J. Am. Chem. Soc. 2020, $142,15673)$, the authors expand the scope of photoinduced enzyme-catalyzed radical cyclizations to chloro-O-alkyloximes. UV/Vis experiments carried out by the authors indicate that the substrate's oxime moiety is crucial for CT complex-formation, enabling radical generation. Whereas generally excellent enantiomeric ratios are obtained under mild reaction conditions, the reaction's scope seems to be limited, as only substrates bearing alkyl residues attached to the oxime carbon gave the corresponding products with high selectivity. 